$\mathbb{T}$ periodica polytechnica

Chemical Engineering

$52 / 1(2008) 11+16$

doi: $10.3311 /$ pp.ch.2008-1.03

web: http://www.pp.bme.hu/ch

(c) Periodica Polytechnica 2008

RESEARCH ARTICLE

\section{Reliability studies in the determination of quantitative covalent fixation of reactive dyes on cellulose}

\author{
Judit Henrietta Nagy / Annamária Kuvik / István Rusznák / Péter Sallai / Ágota \\ Drégelyi Kiss / Sándor Kemény / András Víg \\ Received 2008-01-23
}

\section{Introduction}

About sixty per cent of cellulose textile products are dyed with reactive dyes. The fact that 1150 different reactive dyes have been registered in the Colour Index and this number has been increased by 23 new dyes yearly, demonstrates the mentioned importance [1].

The hydrolysis of reactive dyes simultaneously with their binding by cellulose could not be overcome completely so far [2]. To reduce water pollution and to improve the economy of dyeing by means of increase in the proportion of the fixed dye content has been common interest in dye-houses. To elaborate appropriate dyeing technologies with new types of high fixation reactive dyes are international targets of $R \& D$ activities. This tendency generated the idea to analyse and to compare the accuracy of the most frequently used analytical methods for the determination of dye fixation.

All related published methods are well known also in details. In certain cases dyed samples are dissolved in concentrated sulphuric acid for the evaluation of their dye contents in the reactive dyeing. The absorbance of the obtained solution has been measured subsequent to its dilution by distilled water. The fixed dye content in the dyeing is calculated by relating this absorbance to the initial concentration (through absorbance) of the dye-bath [3]. This procedure is mentioned in this paper as the "Direct Method".

The "Indirect I method" for the calculation of the fixed dye content is based on the measurement of remaining dye content of the dye-bath together with that of the rinsing solutions [4].

"Indirect II" method combines the reflexion measurement of the sample with the absorption measurement of the dye-bath, resulting in $\mathrm{K} / \mathrm{S}$ values [5].

The purpose of our work was to determine precision of three selected methods for measuring the fixed dye content on cotton fabric dyed with heterobifunctional reactive dyes [6].

To compare precision of the studied methods the analysis of variance (ANOVA) technique was chosen [7].

\footnotetext{
András Víg

Organic Chemical Technology Research Group of the Hungarian Academy of Sciences at BME
} 


\section{Materials and methods}

\subsection{Materials and equipments}

Bleached and mercerized cotton fabric (surface density: 109 $\left.\mathrm{g} / \mathrm{m}^{2}\right)$

Two heterobifunctional reactive azo dyes (abbreviated codes $B$ and C) (Table 1 .

- Mathis Labomat BFA-12 laboratory dyeing equipment

- HP UV-VIS 8452 A diodarray spectrophotometer

- DATACOLOR Microflash reflection spectrophotometer

\subsection{Methods}

\subsubsection{Dyeing experiments}

Cotton fabric samples ( $5 \mathrm{~g}$ each) have been dyed in three days, three repeated samples per day with two reactive dyes separately (B and C) in two nominal dye concentrations $(0.6 \mathrm{~g}$ dye $/ 100 \mathrm{~g}$ fabric and $3.0 \mathrm{~g}$ dye $/ 100 \mathrm{~g}$ fabric, liquor ratio $=1: 50$ ). The dyeing procedure is shown by Fig. 1

$18 \mathrm{~B}$ dyeings and $18 \mathrm{C}$ dyeings have been obtained thereafter. The levelness of the dyeings had to be checked one by one. Colour difference was tested at five selected spots in each dyed sample. The obtained within-sample colour difference in each case was negligible $\left(\Delta E_{a b}^{*}<0.3\right)$.

Rinsing in $250 \mathrm{ml}$ different liquids by the following treatments:

1 distilled water at ambient temperature for 5 minutes

2 acetic acid solution $(\mathrm{pH}=5,5)$ at $50{ }^{\circ} \mathrm{C}$ for 5 minutes

3 distilled water at $90{ }^{\circ} \mathrm{C}$ for 5 minutes

4 distilled water at $95^{\circ} \mathrm{C}$ for 5 minutes

5 distilled water at $50{ }^{\circ} \mathrm{C}$ for 5 minutes

6 distilled water at ambient temperature for 5 minutes.

2.2.2 Methods for the determination of the fixed dye content

\subsubsection{Direct method}

$0.1 \mathrm{~g}$ undyed fabric (conditioned before weighting at $65 \%$ relative humidity and $21^{\circ} \mathrm{C}$ ) was dissolved in $10 \mathrm{ml}$ concentrated sulphuric acid at $0^{\circ} \mathrm{C} .7$ dye solutions (from $5 \cdot 10^{-3} \mathrm{~g} / \mathrm{l}$ through $\left.6 \cdot 10^{-2} \mathrm{~g} / \mathrm{l}\right)$ were prepared in $10 \mathrm{ml}$ distilled water from both dyes separately. The concentrated sulphuric acid solutions was mixed very carefully with the respective prepared dye solution prior to their dilution to $25 \mathrm{ml}$ by distilled water. Absorbance vs. concentration calibration curve was constructed for both dyes.

To determine the actual dye content of samples $0.1 \mathrm{~g}$ dyed fabric (from $5 \pm 0,01 \mathrm{~g}$ dyed sample) was dissolved in $10 \mathrm{ml}$ concentrated sulphuric acid at $0^{\circ} \mathrm{C}$. This solution was very carefully poured into $10 \mathrm{ml}$ distilled water and the mixture filled up to $25 \mathrm{ml}$ by distilled water. The same procedure was followed with the undyed fabric sample. The dye content of the studied sample was determined through the difference of absorbances measured for the dyed and undyed samples (dyed $\mathrm{A}_{d}$, white $\mathrm{A}_{w}$, respectively) (Eq. 11.

$$
A_{d}-A_{w}=A_{f}
$$

where $A_{f}$ is the absorbance attributed to the covalently fixed dye content of the studied fabric.

Commercial dyes contain not only the pure dye compound. This was considered by using the calibration function obtained with the same dye product. The fixed dye content of the samples was recalculated for $5 \mathrm{~g}$.

\subsubsection{Indirect I method}

After dyeing the exhausted dye bath and the rinsing liquors were united before diluting the mixture to $2000 \mathrm{ml}$ by distilled water. The fixed dye concentration was calculated from the absorbance of this mixture $\left(A_{u f}\right)$ and that of the initial bath $\left(A_{0}\right)$ (Eq. 2).

$$
c_{\text {fixed }}[\%]=100\left(1-\frac{A_{u f}}{A_{0}}\right)
$$

\subsubsection{Indirect II method}

This method is based upon the combined application of absorption and reflection spectra. The absorbance of the dye bath has to be measured prior to $\left(A_{p}\right)$ and subsequent to $\left(A_{s}\right)$ the dyeing procedure. The dyed fabric sample was taken out from the dye bath and after squeezing and drying its reflection spectrum was measured $\left(R_{1}\right)$. The same dyed fabric was washed carefully with distilled water and dried at $105^{\circ} \mathrm{C}$ and its reflection spectrum was also determined $\left(R_{2}\right)$. The respective $\mathrm{K} / \mathrm{S}$ values have been calculated by means of the Kubelka-Munk equation (Eq. 3).

$$
K / S=\frac{(1-R)^{2}}{2 R}=\alpha c
$$

From the $\mathrm{K} / \mathrm{S}$ values obtained the fixed dye content was calculated as follows (Eq. 4):

$$
c_{\text {fixed }}[\%]=\left[\left(1-\frac{A_{s}}{A_{p}}\right) \frac{(K / S)_{2}}{(K / S)_{1}}\right] n 100
$$

\subsection{Evaluation of the determination methods of the fixed} dye content through analysis of variance

The effect of factors influencing the experimental results and the random error of measurement has been assessed by analysis of variance.

The conditions for applying the analysis of variance method are:

- random fluctuation of residuals (difference between the measured and calculated values) around zero, checked graphically,

- normal distribution of the residuals, checked by Normal probability plot,

- and homogeneous variances. 


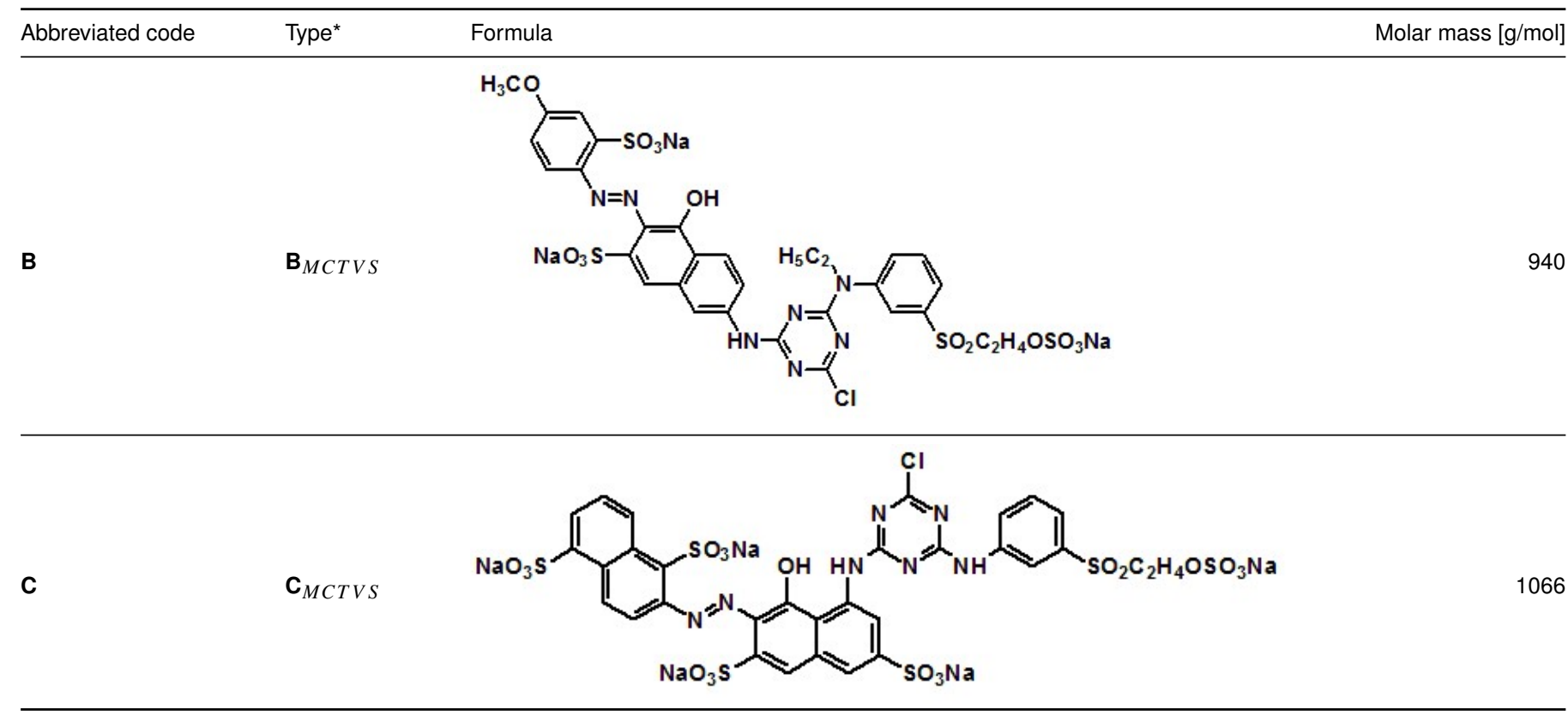

${ }^{\star} \mathrm{MCT}=$ monochloro-triazine, $\mathrm{VS}=$ vinyl sulphonyl

Three factors, which influence the experimental results have been studied in the direct and indirect I methods:

$\alpha$ effect of the day of experiment, random factor,

$B$ effect of the concentration of dye, fixed factor,

$\gamma \quad$ effect of repeated dyeings.

The following model has been used (Eq. 55:

$$
y_{i j k l}=\mu+\alpha_{i}+B_{j}+\alpha B_{i j}+\gamma_{k(i j)}+\varepsilon_{l(i j k)}
$$

where:

$y_{i j k l} \quad$ is the dye proportion obtained on the $i$-th day, with $j$-th concentration, $k$-th repeated dyeing, and $l$-th repeated measurement,

$\mu \quad$ is the mean value of the fixed proportion,

$\alpha_{i} \quad$ is the effect of the $i$-th day,

$B_{j} \quad$ is the effect of the $j$-th dye concentration,

$\alpha \mathrm{B}_{i j} \quad$ is the interaction between the $i$-th day and $j$-th dye concentration,

$\gamma_{k} \quad$ is the effect of the $k$-th repeated dyeing

$\varepsilon_{l(i j k)} \quad$ is the (analytical) measurement error in the $l$-th repeated analysis.

The dyeing experiment was performed under the following conditions: $i=1,2,3$ days, $j=1,2$ dye concentrations and the dyeing experiment was repeated 3 times $(k=1,2,3)$. In the direct method there were not any repeated chemical analysis, thus $l \equiv 1$, while in the indirect methods 3 repetitions have been performed $(l=1,2,3)$.

The concentration was evaluated at 5 different locations on the textile in the indirect II method and this procedure has established a further random factor.

Consequently the model has been modified as follows:

$$
y_{i j k l m}=\mu+\alpha_{i}+B_{j}+\alpha B_{i j}+\gamma_{k(i j)}+\delta_{l(i j k)}+\varepsilon_{m(i j k l)}
$$

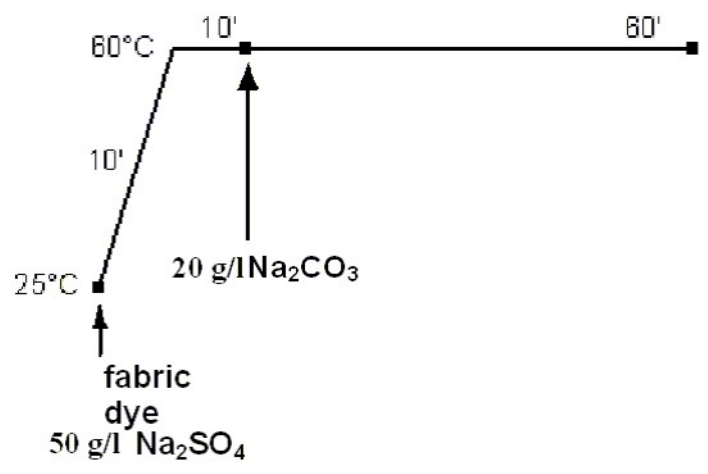

Fig. 1. Dyeing procedure

where:

$\delta_{l(i j k)} \quad$ is the effect of the $l$-th location, random factor, reflecting the inhomogeneity of the fixed dye content along the fabric,

$\varepsilon_{m}(i j k)$ is the (analytical) measurement error in the $m$-th repeated analysis.

The Statistica 7.0 software was used for mathematical analysis.

\section{Results and discussion}

No difference could be distinguished between $\mathrm{B}$ and $\mathrm{C}$ dyeings according to the ANOVA calculations. Consequently detailed discussion follows only for the $\mathrm{C}$ dyeings while only the box-plot will be evaluated in details for the $\mathrm{B}$ dyeings.

For dye $\mathrm{C}$ the residuals (difference between the measured and calculated values) were checked for all 3 methods. The residuals scatter around zero without any systematic behaviour.

The Normal probability plot of residuals is shown in Fig. 2 for $\mathrm{C}$ dyeings.

The residuals in the plot scatter around a straight line, thus the normal distribution of residuals can be accepted. 
a)

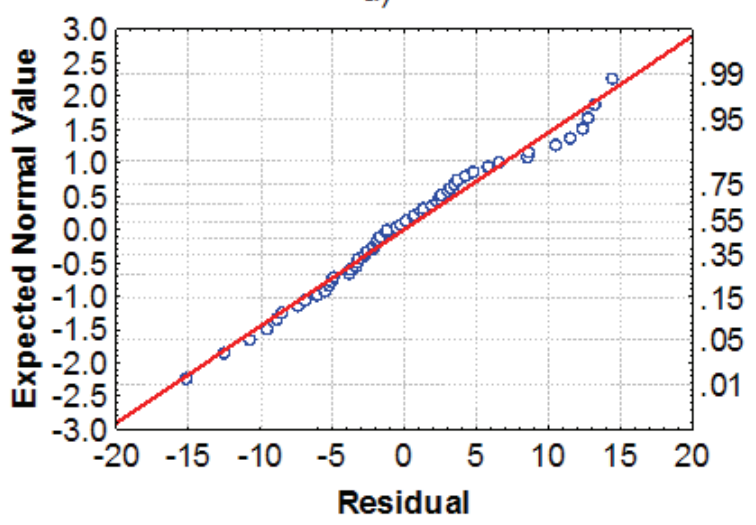

b)

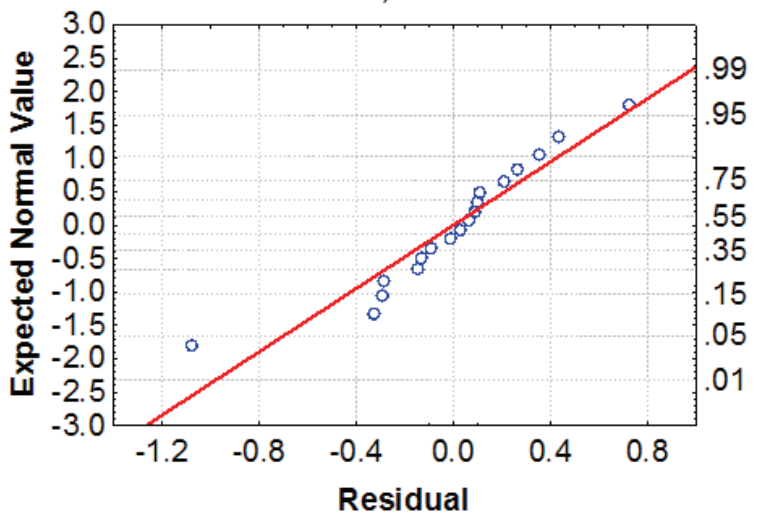

c)

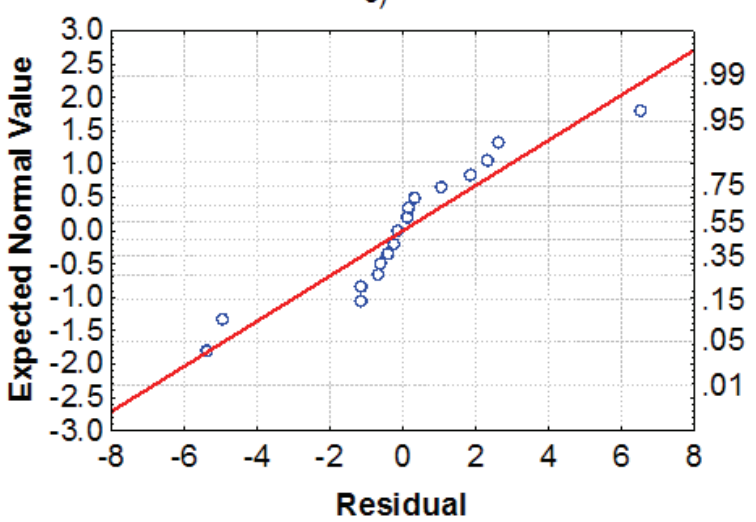

Fig. 2. The probability plot of residuals for $\mathrm{C}$ dyeings calculated by the data obtained by (a) direct method, (b) indirect I method and (c) indirect II method

Results of the Bartlett test supports also the assumption of homogeneity of variances (not shown here).

All conditions of the ANOVA have been fulfilled; consequently its application has been justified.

Tab. 2. Simplified ANOVA table for the evaluation of the direct method for C dyeing

\begin{tabular}{lrrrr}
\hline Factors and Error & DF & MS & F & p \\
\hline$\alpha$ & 2 & 60.313 & 1.21 & 0.452 \\
B & 1 & $\mathbf{4 4 5 . 9 7 8}$ & 8.98 & $\mathbf{0 . 0 9 6}$ \\
$\alpha \mathrm{B}$ & 2 & 49.669 & 2.25 & 0.148 \\
$\gamma$ & 12 & 22.097 & 0.34 & 0.977 \\
\hline Error & 36 & 65.897 & & \\
\hline
\end{tabular}

a)

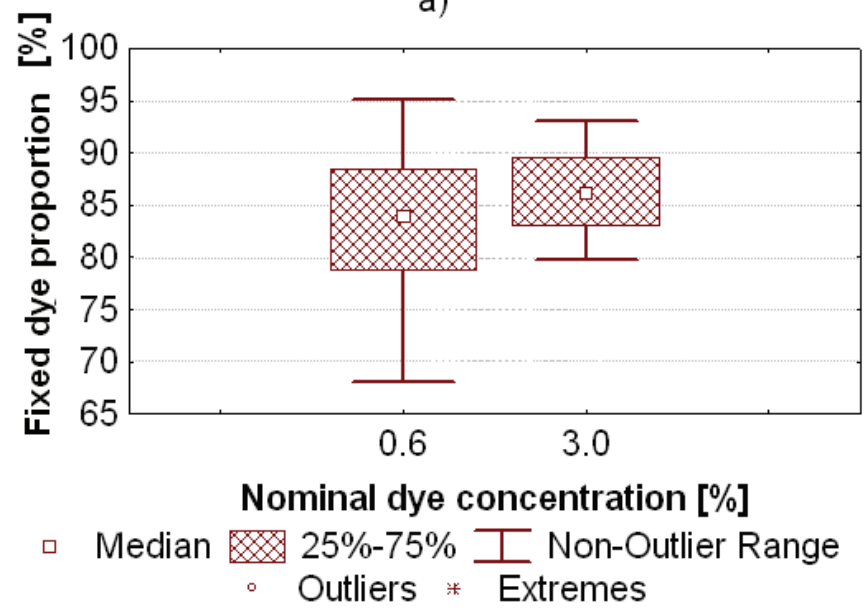

b)

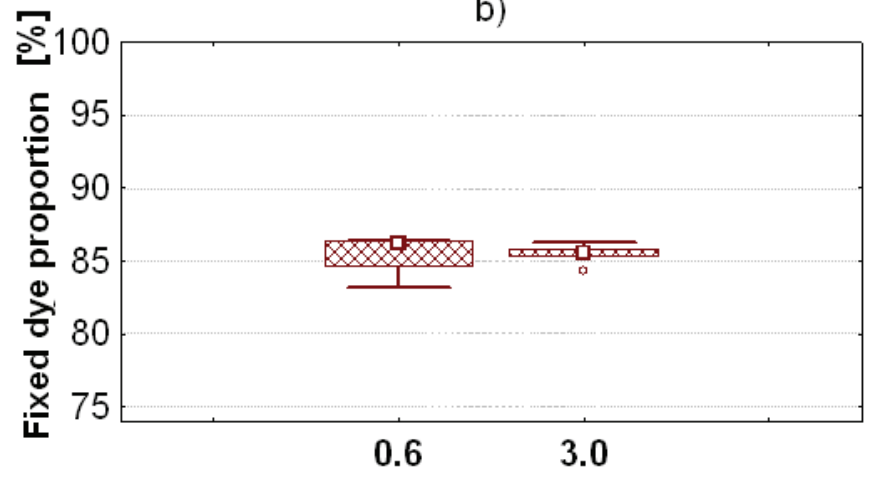

Nominal dye concentration [\%]

- Median 25\%-75\% 工Non-Outlier Range

- Outliers : Extremes

c)

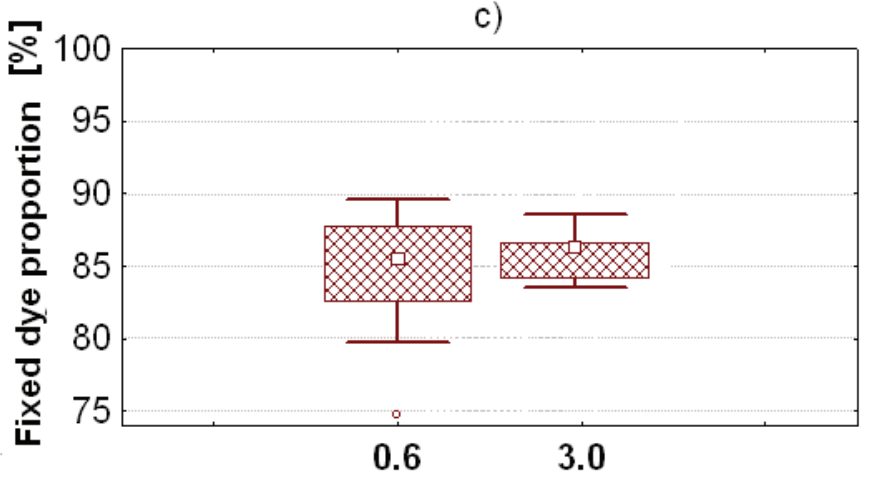

Nominal dye concentration [\%]

Median 25\%-75\% I Non-Outlier Range

- Outliers * Extremes

Fig. 3. Median-quartile box-plots for B dye (a: direct method, b: indirect I method, c: indirect II method)

Where

MS mean square,
$\mathrm{p} \quad \begin{aligned} & \text { probability value (if it is small, the null hypothesis of } \\ & \text { lack of effect is rejected), }\end{aligned}$
DF degree of freedom, depends on the number of measure-
ments and the number of levels of factors
the F test statistic from the ratio of mean squares.


a)

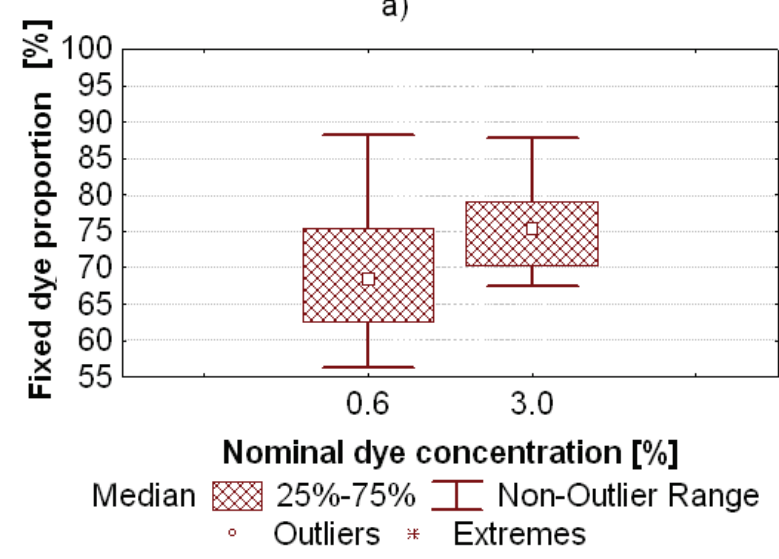

b)

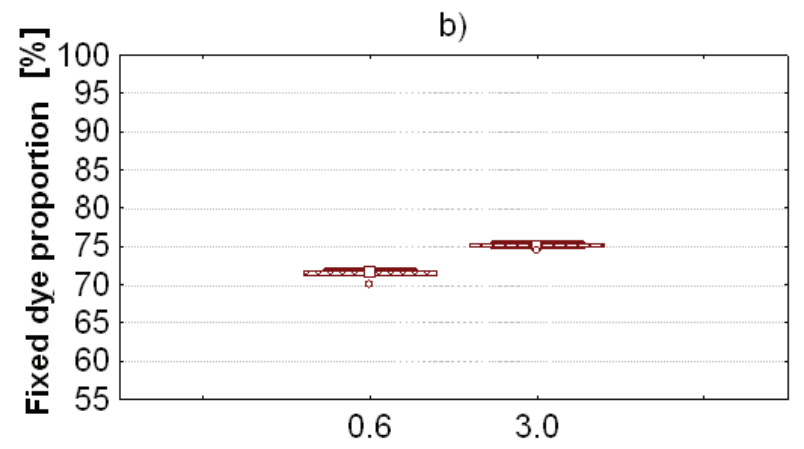

Nominal dye concentration [\%]

- Median 25\%-75\% I Non-Outlier Range

- Outliers * Extremes

c)

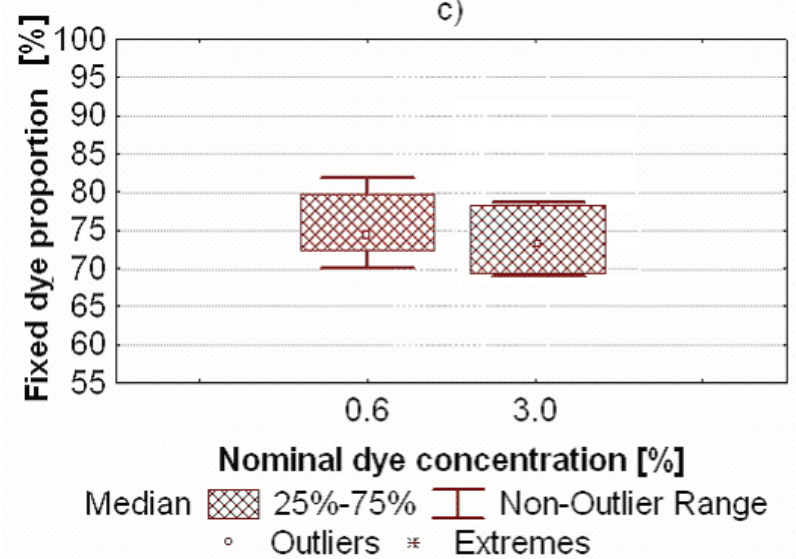

Fig. 4. Median-quartile box-plots for $\mathrm{C}$ dye (a: direct method, b: indirect I method, c: indirect II method)

From the results (Table 2) it can be concluded that none of the factors has significant effect at 0.05 level. The variance of the measurement was $65.9 \%$ for the direct method, thus the standard deviation of measurement error can be estimated as $8 \%$.

The corresponding value for the B dyeing has been $5.2 \%$.

The day factor $\left(\alpha_{i}\right)$ has no significant effect on the calculated results as $p>0.05$ whereas, the impact of the nominal dye concentration proved to be significant $(p<0.05)$ (Table 3 ).
Tab. 3. Simplified ANOVA table for the evaluation of the indirect I method for $\mathrm{C}$ dyeing

\begin{tabular}{lrrrr}
\hline Factors and Error & DF & MS & F & p \\
\hline$\alpha$ & 2.000 & 0.571 & 15.14 & 0.062 \\
B & $\mathbf{1}$ & $\mathbf{6 0 . 9 0 4}$ & $\mathbf{1 6 1 6 . 6 8}$ & $\mathbf{0 . 0 0 1}$ \\
$\alpha \mathrm{B}$ & 2 & 0.038 & 0.18 & 0.835 \\
\hline Error & 12 & 0.205 & & \\
\hline
\end{tabular}

Where

MS mean square,

$\mathrm{p}$ probability value (if it is small, the null hypothesis of lack of effect is rejected),

DF degree of freedom, depends on the number of measurements and the number of levels of factors

$\mathrm{F}$ the $\mathrm{F}$ test statistic from the ratio of mean squares.

Tab. 4. Simplified ANOVA table for the evaluation of the indirect II method for C dyeing

\begin{tabular}{lrrrr}
\hline Factors and Error & DF & MS & F & p \\
\hline$\alpha$ & 2 & 2.530 & 1.998 & 0.334 \\
B & 1 & 9267.357 & 7318.157 & 0.000 \\
$\gamma$ & 12 & 0.327 & 1.071 & 0.397 \\
$\alpha \mathrm{B}$ & 2 & 1.266 & 3.876 & 0.050 \\
$\delta$ & 72 & 0.305 & & \\
\hline Error & 0 & 0 & & \\
\hline
\end{tabular}

Where

MS mean square,

$\mathrm{p} \quad$ probability value (if it is small, the null hypothesis of lack of effect is rejected),

DF degrees of freedom, depends on the number of measurements and the number of levels of factors

$\mathrm{F} \quad$ the $\mathrm{F}$ test statistic from the ratio of mean squares.

The estimated variance of repetitions was $0.205 \%$, and this included both the fluctuation due to replicated dyeing and to the repeated chemical analysis, thus the standard deviation of measurement error could be estimated as $0.453 \%$.

The corresponding value for the B dyeing has been $0.52 \%$.

The dye concentration has significant impact on the experimental data $(p<0.05)$ also in case of indirect II method (Table 47. It is found that the use of reflectance does not give reliable results at high $\mathrm{K} / \mathrm{S}$ values.

The estimated variance for differences among the measured data has been $0.305 \%$, thus the standard deviation of measurement error can be estimated as $0.552 \%$.

The corresponding value has been $0.344 \%$ for the B dyeing.

The nature of variation of the measurement results is well visualized in the median-quartile box-plot. The small rectangle in the middle of the box is the median, the edges of the box are the quartiles, the whiskers show the range of data. This kind of plot may uncover extent and asymmetry of the distribution as well. The above mentioned data are shown in Figs. 3a, 3b and $3 \mathrm{c}$ for 
Tab. 5. Summarised data establishing conclusions

\begin{tabular}{|c|c|c|c|c|c|c|c|}
\hline \multicolumn{2}{|r|}{ Dye } & \multicolumn{6}{|c|}{ Method } \\
\hline \multirow[b]{2}{*}{$\begin{array}{l}\text { Abbreviated } \\
\text { code }\end{array}$} & \multirow[b]{2}{*}{$\begin{array}{c}\text { Nominal dye concentration } \\
\text { [g dye } / 100 \mathrm{~g} \text { fabric] }\end{array}$} & \multicolumn{2}{|c|}{ Direct } & \multicolumn{2}{|c|}{ Indirect I } & \multicolumn{2}{|c|}{ Indirect II } \\
\hline & & $\begin{array}{l}\text { Fixed dye } \\
\text { content[\%] }\end{array}$ & $\begin{array}{c}\text { ANOVA variance } \\
{[\%]}\end{array}$ & $\begin{array}{l}\text { Fixed dye } \\
\text { content[\%] }\end{array}$ & $\begin{array}{c}\text { ANOVA variance } \\
{[\%]}\end{array}$ & $\begin{array}{l}\text { Fixed dye } \\
\text { content[\%] }\end{array}$ & $\begin{array}{c}\text { ANOVA variance } \\
{[\%]}\end{array}$ \\
\hline \multirow{2}{*}{$B$} & 0.6 & 83.3 & \multirow{2}{*}{5.20} & 85.3 & \multirow{2}{*}{0.52} & 84.5 & \multirow{2}{*}{3.20} \\
\hline & 3.0 & 86.0 & & 85.4 & & 86.5 & \\
\hline \multirow{2}{*}{ C } & 0.6 & 69.5 & \multirow{2}{*}{8.12} & 71.4 & \multirow{2}{*}{0.45} & 75.5 & \multirow{2}{*}{3.12} \\
\hline & 3.0 & 75.2 & & 75.1 & & 73.3 & \\
\hline
\end{tabular}

B dye and on Figs. 4a, $4 \mathrm{~b}$ and $4 \mathrm{c}$ for $\mathrm{C}$ dye. The values situated beyond the whiskers have to be considered as outliers (extremes are statistically not valuable abnormal data).

\section{Conclusions}

The dependence of the fixed dye content on two dye concentrations and the respective method dependent variance components are shown for B and $\mathrm{C}$ dyes in Table 5 .

Nearly equal fixed dye content has been found by the three methods. The fixed dye content proved to be independent of the nominal dye concentration in the selected range probably therefore because even the higher dye concentration was not close to saturation.

The variance component values however are different for the three methods.

The most precise was the indirect I method. Less favourable was the indirect II method and the worst one was the direct method. The last one was in addition the most complicated and unfavourable in all respects.

For the explanation of the deviation in the fixed dye content between the hetero bifunctional reactive $\mathrm{B}$ and $\mathrm{C}$ dyes the difference in chromophore structure might be most probable.

\section{References}

1 Burkinshaw SM, The dyeing and printing of nylon 6,6 with reactive dyes, International Symposium (Manchester), 2004. CD Proceedings. A Celebration of 50 Years of Innovation.

2 Papic S, Koprivanac N, Bozic LA, Removal of reactive dyes from wastewater using $\mathrm{Fe}$ (III) coagulant, Journal of the Society of Dyers and Colourists 116 (2000), 352-359.

3 Shukla SR, Mathur L, Chatterjee L, Selecting reactive dyes for all-in dyeing of polyester/cotton blends, Journal of the Society of Dyers and Colourists 114 (1998), 254-257.

4 Cai Y, Pailthrope MT, David SK, A new method for improving the dyeability of cotton with reactive dyes, Textile Research Journal 69 (1999), 440-446.

5 Lewis DM, Yao J, Crosslinking a hydroxyethylsulphonyl dye on cotton to achieve covalent fixation in a long-liquor process, Coloration Technology 116 (2000), 285-290.

6 Soleimani-Gorgani A, Taylor J A, Dyeing of nylon with reactive dyes. Part 3: Cationic reactive dyes for nylon, Dyes and Pigments 76 (2008), 610-623.

7 Careri M, Casnati M, Guarinoni A, Mangia A, Mori G, Pochini A, Ungaro R, Study of the behavior of calix 4larene-based sodium-selective electrodes by means of ANOVA, Journal of Analytical Chememistry 85 (1993), 3156-3160. 